Article

\title{
How the ENGOs Can Fight the Industrial/Business Lobby with Their Tools from Their Own Field? ENGOs Participation in Emissions Trading Market
}

\author{
Elias Asproudis ${ }^{1, *}$ and Thomas Weyman-Jones ${ }^{2}$ \\ 1 Department of Economics, School of Management, Bay Campus, Fabian Way, University of Swansea, \\ Swansea SA1 8EN, UK \\ 2 School of Business and Economics, Leicestershire, Loughborough University, Loughborough LE11 3TU, UK; \\ T.G.Weyman-jones@lboro.ac.uk \\ * Correspondence: Ilias.Asproudis@swansea.ac.uk
}

Received: 12 March 2020; Accepted: 10 July 2020; Published: 16 October 2020

check for updates

\begin{abstract}
In this article, we explain how several environmental groups are attempting to influence environmental policy by changing the total amount of pollution allowed within the tradable emissions market. We highlight the case where environmental groups may participate in strategic behaviour to resemble co-operative coalition behaviour. We present an interesting way that environmental groups can encourage their goal of reducing pollution, contrary to the industrial/business groups' desires. This is a major concern in our world, and such a new approach could be adopted more broadly.
\end{abstract}

Keywords: emissions; tradable allowances; third parties; environmental groups; overallocated allowances; strategic behaviour

\section{Introduction}

In recent years, there has been a growth in the literature that explores the participation of third parties (such as communities, citizens, environmental groups) in the tradable allowances market. This includes markets for emission permits and markets for water quality trading, (for examples, see [1] for environmental groups participation in emission markets; [2] for communities participation in tradable permits markets; and [3] for third parties like environmental groups participation in water quality trading markets). In particular, third parties can participate in the European Union Emissions Trading System (EU ETS), and may purchase or sell allowances (e.g., $\mathrm{CO}_{2}$ allowances) within the trading process, as an extra player separate to the profit-making firm [1]. Consequently, their participation may drive the market to a lower quantity of allowances/emissions than the potential maximum level of emissions as this is allowed by the regulator.

The tradable emissions market allows firms to calculate the price that they would be willing to pay to be allowed to engage in each level of polluting. This system allows them to equate the marginal cost and the marginal benefit of polluting, as is proposed by standard economic theory.

This paper explains the method used by several environmental groups to move past the usual approaches of trying to influence environmental policy through lobbying (for lobby and other targets of environmental groups, see [4]). Instead, environmental groups are utilising the markets for tradable emissions allowances to influence the total amount of pollution allowed, and to press the firms to adopt or invest in less-polluting technology. Amongst other issues, the central subject that we aim to examine is how the environmental impact of business/industrial activities can be mitigated by the action of Environmental Non-Governmental Organisations (ENGOs) using the tradable allowances market. In addition, we explore when right timing for a coalition of ENGOs to participate in the 
tradable allowances market to purchase could be, and how to withdraw allowances so that firms are encouraged to reduce their environmental impact.

Since the EU ETS allows any stakeholder to purchase such allowances, environmental groups can purchase and retire emission allowances. Thereby, they are decreasing the official total and maximum amount of pollution in the environment, as was agreed by the international environmental agreements (for third parties' participation in tradable allowances market, see $[5,6]$ ). We explore the possible impact of a coalition of environmental groups that can purchase and withdraw pollution allowances in EU ETS, and we propose that this approach is able to decrease the amount of maximum allowed pollution on that continent. This effect could have an impact on the business and industrial sector, especially in this industry, so that emissions allowances and environmental abatement technology are substitutes. Examples of this type of industry could be refineries, energy production sector with fossil fuels, and more generally, the heavy industry sector with mainly energy intensive characteristics.

We particularly focus on the role of environmental groups/ENGOs as a possible dominant third-party influencer. There are examples of ENGOs that focus on the purchasing and retirement of allowances as a tool to press firms to adopt greener and less polluting technologies. Amongst others, examples of U.S. ENGOs include the Clean Air Conservancy Trust, Acid Rain Retirement Fund, Adirondack Council, Environmental Resources Trust (for more details for their participation see http://www.epa.gov/airmarkets/trading/buying.html\#1 (date access: 13 July 2013). Furthermore, ENGOs not only invite the public to donate to them so that they may withdraw the allowances from the market; but they also provide the public with necessary information concerning their participation in the ETS (see the European ENGO Sandbag (Sandbag.org)—we can read in the website for the history of the specific ENGO "Sandbag was founded in 2008 by Baroness Bryony Worthington to shine a light on what was really going on in emissions trading in the EU and to enable people to buy and remove the surplus carbon allowances from the EU ETS. (Date access: 26 July 2019)).

This is a new approach to handling environmental concerns, and one which could be employed globally, as we face issues, such as global warming, brought on by environmental mismanagement. Furthermore, we focus on the case where the organisations involved may participate in strategic behaviour that would resemble co-operative coalition behaviour. Specifically, in our study we highlight the possibility of a coalition of environmental groups (for example, the Green 10-a coalition of the 10 largest European environmental NGOs or CAN Europe) to follow a strategic move in the EU ETS to purchase and withdraw several tradable allowances (The organisations which participate in Green 10 are; Birdlife International, CEE Bankwatch Network, Climate Action Network Europe (CAN-E), European Environment Bureau (EEB), Transport and Environment (T\&E), Health and Environment Alliance, Friends of the Earth Europe (FoEE), Greenpeace, Naturefriends International (NFI), WWF European Policy Office (WWF-EPO). For further details see http://www.green10.org (date access: 8 November 2017)).

In general, this paper presents an interesting way that environmental groups can creatively approach their goal of reducing pollution. This is certainly currently a major concern in our world, and such a new approach might be one that could be adopted more broadly.

The rest of the paper is divided in four parts. In the next part we present the methodology and the research approach. Then, in part three we present the background regarding the definition of NGOs and we briefly analyse the basic function and the origins of the European ETS. In doing so, we present an overview to the reader. Moreover, we explore the literature about third party participation in the tradable allowances market, and more specifically, environmental groups' participation and strategy. In the fourth part we present the data and we discuss the results on the possible dynamic of the ENGOs co-operative coalition and strategic behaviour within the ETS and how these may benefit the regulator. Finally, the conclusions are included in the fifth part. 


\section{Methodology}

To present the possibility of the ENGOs strategic co-operative behaviour we explore previous years' data where this strategic co-operative coalition behaviour could be effective in terms of timing and cost. Specifically, we collected secondary data and we follow a holistic, but also a descriptive approach to explain the possible strategy of the ENGOs and the best timing of the collective strategy/movement. The data that we collected on the movements on the price of permits and the surplus allowances suggest that devising a possible strategy for ENGOs must satisfy several constraints.

We consider the following issues are important in thinking about the strategy that could be adopted by a group of ENGOs in purchasing and retiring tradable allowances. (i) The regulatory authority must allocate a set of allowances that is not greater than the politically determined emissions target: $A \leq E^{*}$, but without setting a level of allowances that will make the industrial lobby, e.g., energy producers as a group financially unviable which would damage economic welfare in general. (ii) ENGOs could also enter the market, and subject to their aggregate budget constraint can purchase and withdraw allowances from the allowances market. (iii) The ENGOs, by purchasing and withdrawing allowances, will be able to raise the price of allowances sufficiently high so the firms will prefer to invest in environmentally friendly technology, rather than to purchase more of the expensive allowances. Therefore, abatement technology becomes more attractive for the firms.

The secondary data cover all the three period of the ETS-phase one (2005-2007), phase two (2008-2012), and phase three (2013-2020). For these periods we include the price of the allowances in the allowance market and the total allocated allowances by the regulator to the firms which are separated to two different categories, the freely allocated allowances, and the auctioned allowances. Furthermore, for each period we include the analogous verified emissions (or the real level of emissions) and the over-allocated allowances (or the number of the allowances more than the real emissions).

Therefore, we focus on these periods where the tradable allowances had relativity low price, and therefore, were attractive from a financial perspective to purchase. That timing could encourage the decision of a group of ENGOs to collaborate and to move with a strategic plan to achieve the minimisation of the maximum allowed emissions. This type of behaviour is well known in the profit orientated markets where firms agree to use cartel-behaviour or collusion in terms of prices to achieve higher profits and against to the consumers' welfare. This is illegal, or against to the official market regulations, and the authorities enforce a penalty on these firms if they follow this strategy. However, according to our knowledge, similar behaviour is not prohibited in the non-profit market. ENGOs do not have an obligation to follow the same legislations or regulations like the firms. In other words, ENGOs could follow this type of strategic behaviour without any possible penalty or legal restriction. Therefore, this study contributes to the literature and presents the possibility of ENGOs collusion behaviour in the ETS, as well as focusing on the timing of this behaviour. When is the right timing for the ENGOs strategic collaborative movement?

This is an emerging issue in the area of Business and Environment (i) because of the strategy of the ENGOs against to the industry/business groups, and (ii) because the ENGOs can fight the industrial lobby with their tools from their own field.

\section{Background}

\subsection{Non-Governmental Organisations: Definition and Categories}

Before we continue to the other parts of this paper it is reasonable and useful to clarify what type of organisations belong to the category of environmental groups. Initially, we adopt from [7] their definition for Non-Governmental Organisations (NGO) which is based on the World Bank: NGOs are private organisations "characterized(sic) primarily by humanitarian or co-operative, rather than commercial, objectives that pursue activities to relieve suffering, promote the interests of the poor, protect the environment, provide basic social services, or undertake community development". 
However, in order to focus on the ENGOs and not on other NGOs we adopt the taxonomy classification as this is provided by [8], and specifically the UN Handbook on Non-Profit Institutions in the System of National Accounts. Therefore, it will be clear to the reader what types of non-profit or non-governmental organisations are included in this study. According to the Handbook, environmental groups belong to the category 5, and there are two subcategories or sub-groups Environment and Animal Protection. For each subgroup, there are three descriptions (or definitions) based on each organisation targets. "Pollution abatement and control. Organisations that promote clean air, clean water, reducing and preventing noise pollution, radiation control, treatment of hazardous wastes and toxic substances, solid waste management and recycling programmes. Natural resources conservation and protection. Conservation and preservation of natural resources, including land, water, energy and plant resources for the general use and enjoyment of the public. Environmental beautification and open spaces. Botanical gardens, arboreta, horticultural programmes and landscape services; organisations promoting anti-litter campaigns; programmes to preserve the parks, green spaces and open spaces in urban or rural areas; and city and highway beautification programmes". Similarly, for the sub-group Animal Protection, we read Animal protection and welfare. Animal protection and welfare services; includes animal shelters and humane societies. Wildlife preservation and protection includes sanctuaries and refuges. Veterinary services include animal hospitals and services provide care to farm and household animals and pets (p. 95).

Therefore, hereafter the above types of groups are the ENGOs that we referred to at the continuing of this study.

\subsection{European Union Emissions Trading System: A Brief Look}

The use of the tradable allowances market like the ETS is based on the economic theory of [9] where the negotiations between the polluter and the polluting could be a way for the market to achieve an equilibrium level of emissions acceptable from both parties and without government intervention in the function of the market. More studies adopted the idea of the tradable allowances market as a policy instrument for the reduction of the air emissions, and this tool is used for the sustainable management of the water in a river or sustainable management of common-pool resources like fisheries, as well as for sustainable use of land rights (for some relative studies see [10-19].

Generally, the ETS aims to improve the environmental, economic, business, and sustainable market development without government intervention, and its function is based on the standard economic theory of the invisible hand. According to [20], "sustainable development is development that meets the needs of the present without compromising the ability of future generations to meet their own needs" (see [21]).

The ETS was adopted by the European Union after the signing of the Kyoto Protocol. Specifically, several countries participated in the Conference of the Parties (COP) to decide on the best strategies and tools against global warming. In 1997 COP 3 took place in Kyoto from which emerged the Kyoto Protocol (1998). The participant countries agreed to reduce the level of greenhouse gases by $5 \%$ below the level of the analogous emissions from the year 1990. The function and use of the EU ETS is a mechanism to reinforce the Kyoto Protocol (1998) in creating a demand/supply market for emission reductions. We present the basic 'picture' to the reader regarding the Kyoto Protocol and the ETS. For more details and analysis on the Kyoto Protocol and for a further look on the meetings, documents and decisions see $[22,23]$ and the analogous website from [24]. http://unfccc.int/kyoto_protocol/items/2830.php (date access 11 August 2017). [22] describes in more detail the meetings; decisions; legislative documentation and conferences leading up to the first application of EU ETS in this respect.

According to the baseline agreement on tradable allowances, firms can participate in the transactions of their allowances within the analogous allowance market. However, the total quantity of allowances cannot exceed the maximum level of emissions, or in other words, the cap. This is, the regulator sets the cap and the firms can trade (sell or buy) the available allowances, this system is also known as cap and trade. If a firm has more allowances than emissions for a specific period, then the 
firm can sell the excess allowances (through the allowances market) to other firm(s) that may have more emissions than allowances. In this way also, a firm can purchase extra allowances via the allowances market. This may reflect higher production levels or higher emitting industries. This price-based approach is designed to motivate investment in less polluting technologies towards the overall reduction of emission levels (e.g., $\mathrm{CO}_{2}$ emissions). At the end of each trading year (or period) the regulator enforces a penalty on any firm that has greater emissions than allowances. Thus, the allowance market itself should induce change with minimal government intervention. For more details on the European ETS, the reader could see [25] and the other studies that cited in that paper, as well as the studies from Jorgen Wettestad with his colleagues $([26,27])$.

Finally, although the design and application of ETS was aimed at the sustainability of the market and the environment, it did have some weaknesses that could lead to inefficiencies. For example, the way that regulator will allocate the allowances to the firms has promoted many discussions. Mainly, three different approaches for the allocation of the allowances: (i) Grandfathered allowances, where the regulator allocates the allowances based on the firms' historical emissions, free of charge; (ii) auctioning where firms will bid in order to buy allowances; and (ii) mixed. Specifically, as it is noted in [25] "Grandfathering of allowances in the EU-ETS has led to perverse economic results: [D]ue to extensive lobbying activities more allowances than needed were allocated in the first trading period, which led to a vast decline in the allowances price ([28]). Furthermore, large emitters charged their customers for the allowances, and thus, received high windfall profits $([28,29])$. For the sake of our discussion, the most important aspect of the current design of the EU-ETS is that the allowance allocation method is not as efficient as it could be, even though the superiority of auctioning over grandfathering was known ex-ante." This inefficiency makes the participation of third parties like ENGOs more important, since they could reduce the number of the available allowances in the market, which was in excess as mentioned above, and could lead to a reduction of the inefficiencies. Before we explain in the next part who can participate in the European ETS, it is useful to present the next table for the allocation of the allowances and the way that the regulator allocated the allowances during different periods (Table 1).

Table 1. Allowances of $\mathrm{tCO}_{2}$-eq. in EU ETS for all stationary installations.

\begin{tabular}{cccc}
\hline & $\begin{array}{c}\text { Total Allocated } \\
\text { Allowances }\end{array}$ & $\begin{array}{c}\text { Freely Allocated } \\
\text { Allowances }\end{array}$ & $\begin{array}{c}\text { Allowances } \\
\text { Auctioned or Sold }\end{array}$ \\
\hline $\begin{array}{c}\text { Total 1st trading period } \\
\text { 2005-2007 }\end{array}$ & $6,369,571,429.00$ & $6,321,358,655.00$ & $8,511,250.00$ \\
\hline $\begin{array}{c}\text { Total 2nd trading period } \\
\text { 2008-2012 }\end{array}$ & $10,411,472,031.00$ & $9,998,487,739.00$ & $442,283,214.00$ \\
\hline $\begin{array}{c}\text { Total 3nd trading period } \\
\text { 2013-2020 }\end{array}$ & $11,457,702,320.00$ & $6,516,494,320.00$ & $4,941,208,000.00$ \\
\hline
\end{tabular}

Source: https://www.eea.europa.eu/data-and-maps/dashboards/emissions-trading-viewer-1.

From the above table, we observe that the regulator has allocated free (grandfathered) and auctioned allowances during the three trading periods in the EU ETS. The auctioned or sold allowances were relatively small in comparison with the freely allocated (grandfathered) allowances during the first trading period (2005-2007), but in the third period (2013-2020) the number of the auctioned allowances increased significantly.

\subsection{Who Can Participate in the EU ETS?}

The European tradable allowances market is open to all possible players or agents. European legislation, documents and official statutes allow everyone to participate in the European ETS. As such, not only are those who create pollution within the system, but so are stakeholders and people who suffer because of the pollution. Therefore, third parties (such as Non-Governmental Organisations (e.g., environmental groups), legal persons, citizens, consumers, schools, unions, associations and 
bodies, etc.) are all able to participate in the allowances market. They can: (a) Purchase allowances from the market; (b) sell allowances to the market; or (c) purchase and withdraw allowances from the market. There are brokers available to the public which can purchase permits for their clients. Moreover, some ENGOs following the same way are inviting the public to purchase and withdraw emissions' permits (for example, Sandbag.org, a British ENGO).

Several important documents confirm third parties' free entrance and participation in the emissions trading system. For example, the instruction [30], allows environmental groups (Non-Government Organisations) to purchase and withdraw allowances from the market (Page 12; Paragraph 13, 'Distribution and Publication of Allowance s'). E.C. COM (2001) 581 final "Proposal for a directive of the European Parliament and of the Council establishing a scheme for greenhouse gas emission allowance trading within the community and amending council directive 96/61/EC." Furthermore, a report about the participation by legal persons in the allowances market originates from [31] FCCC/CP/2001/2/Addition 4. Page 27, paragraph 21 (b)). Moreover, within the. [32] any legal or natural person can participate in the emission trading market. Directive 2003/87/E.C. article 3, paragraph (g) “Directive 2003/87/E.C. of the European Parliament and of the council of 13 October 2003 establishing a scheme for greenhouse gas emission allowance trading within the community and amending council directive 96/61/E.C."

\subsection{Strategy and Tradable Allowances of Environmental Groups}

As already ascertained, everyone can participate in the ETS, even individuals as citizens. When individuals have shared interests because of firms' or firm action, then interest groups can form based on common cause or principle. These tend to be more effective in reacting against polluters. We focus on a specific interest group with high sensitivity to environmental protection-the environmental groups.

Characteristic of the environmental groups are the methods which they use in their strategy: activism and lobbying. For a further look on the transnational environmental activist groups in the international politic arena, with examples on activism, see [33] and for lobby and campaign see [24]. As far back as the 1980s environmental groups in U.S.A became supporters of emission allowances system (see [13]). Progressing into the 1990s, environmental groups' acquired new methods to pursue their aim of environmental protection. This strategy appeared on the homepage of Acid Rain Retirement Fund (A.R.R.F., 1997): “As we retire more allowances, the price will go up. Polluting companies will need to bid larger amounts of money to continue polluting. As the price of polluting goes up, companies will be more inclined to invest money in technologies that remove pollution before it reaches the smokestack". Similarly, Clean Air Conservancy (C.A.C.) followed the same spirit: "Each allowance we retire represents one ton less of $\mathrm{SO}_{2}$ that will find its way into the environment". The source of this information emanates from [34] See http://acidrainretirementfund.org/ arrf.htm\#mission (date access 8 September 2012) and https://www.theguardian.com/prius/partthree/ story/0,,1322030,00.html (date access: 8 November 2017) and https://tcfonline.clevelandfoundation. org/catalog/org.shtml?org_id=8549 (date access: 12 July 2013). From the later website we can read that 'In 2003, the Clean Air Conservancy (CAC) established the Clean Air Conservancy Trust to hold its retired allowances. Today, it holds over 7 billion pounds of $\mathrm{SO}_{X}, \mathrm{NO}_{X}$ and $\mathrm{CO}_{2}$, and is one of the largest banks of retired credits and allowances' where from the ARRF's website we read 'The Acid Rain Retirement Fund is a nonprofit corporation that uses 100\% of the money donated to buy pollution allowances. No portion of a donor's money will be used for administrative purposes unless the donor designates it so. We seek to bid on and remove as much pollution as possible from the environment'.

Allowances in environmentalist's hands confer the right not to accept more pollution emissions from firms and a democratic reaction like this is possible only by the public's free participation in the allowances market without restrictions. This opinion is confirmed [35], who argue that the environmentalists' participation in ETS from an ethical viewpoint lends a democratic character to the allowances system. Hence, the environmental groups, independently of the type of distribution 
system (auctioned or grandfathered) selected by the government, could purchase, and withdraw allowances ([13,36,37] and describe the environmentalists' reaction to the emission's tradable allowances application in U.S.A. They argue that the environmentalists had been opposed to the early applications of the Environmental Protection Agency (E.P.A.) emissions trading program (in the 1970s and 1980s), but later become major proponents of tradable allowances after the control of acid rain (later 1980s). In addition, [38] points out that some environmental groups (organisations) have economically incentivised approaches in their strategy for environmental protection. Initially, the environmentalist's participation in the ETS became real in the U.S.A. In the U.K., the British NGO, Sandbag, collects charitable donations to purchase and withdraw allowances from the European Emission Trading System.

From the historical applications of tradable allowances in the U.S.A., we have important information which could explain environmentalists' targets or the reasons for this participation, as well as their effects in the allowances system and market.

The environmental group's participation started in the U.S. almost two decades earlier. Some examples are: Clean Air Conservancy Trust; Acid Rain Retirement Fund; Adirondack Council and Environmental Resources Trust. For more information: http://www.epa.gov/airmarkt/traiding/ buying.html. (date access: 8 September 2012). These groups used donated funds to purchase and withdraw emission allowances in order to reduce the level of the maximum emissions in the atmosphere. In the literature, some empirical papers do confirm and analyse the third parties' participation in the American tradable allowance's markets.

Ref [5] focuses on the third parties' (i.e., mainly the environmental groups) participation in the sulphur emissions trading program between the years 1993 and 2005. She concludes that the number of withdrawn allowances is not particularly high relative to the total number of available allowances in the market. However, the amount of money spent by individuals and groups for the reduction of the emissions "reflects a significant monetary sacrifice on the part of these groups" (p. 388). Ref [6] through an empirical analysis of the auction of tradable emissions $\left(\mathrm{SO}_{2}\right)$ in the 1990s, had focused on the buyers' behaviour and argued that the third parties (like environmental groups, etc.) used to offer very high prices for the allowances acquisition. The possible explanations for this behaviour, according to the authors are: (a) The non-awareness about the market's function; (b) the certainty of the allowances property; and (c) the buyer's appreciation that it was plausible for some reason to offer high prices. Ref [39] compared the design of two different antipollution programs (SAT and RECLAIM) in which the third parties' participation in allowances market confirmed the political acceptability and the public correspondence for environmental improvement. Sulfur Allowance Trading Program (SAT) for the decreasing of $\mathrm{SO}_{2}$ and South Californian Regional Clean Air Incentives Market (RECLAIM) for the decreasing of $\mathrm{SO}_{X}$ and $\mathrm{NO}_{X}$.

Ref [40] presents the difficulties of the tradable allowance's application, but also comments on the system's benefits, where he includes the allowance's ownership by the environmental organisations. Ref [41] focused on the experience of the tradable allowances' application in air, water and fisheries and concluded that the environmental groups had purchased and withdrawn allowances in the acid rain allowances market.

The environmentalists have one main aim: They want to minimise the firms' negative externalities or emissions. As it was analysed earlier in this paper, the environmentalists participate in the ETS to purchase and withdraw allowances from the market. Retiring allowances decrease the available supply of allowances, and by the economic principles (of supply and demand) this action drives prices of allowances up. For a diagrammatic approach, see [5,42].

Hence, for the ENGOs, the purchasing of the over-allocated allowances is an opportunity that can lead to a possible lower level of emissions. 


\section{Results and Discussion}

ENGOs Co-Operative Coalition and Strategic Behaviour in Tradable Allowances Market. When Is the Right Timing for Strategic Collaborative Movement?

We have explored third party participation in the tradable allowances systems, and specifically, we focused on the ENGOs. In this section, we discuss the potential role of environmental groups in EU ETS as determinants on the availability and quantity of allowances in the emission allowances market. This is coupled with the potential possible benefits for the regulator. Following the literature and the experience from the application of the EU ETS, we examine if and how environmental groups or ENGOs could have a coalition with strategic behaviour in order to purchase and withdraw allowances from the European allowances market. To explore the best timing for the strategic collaborative movement, we need to look at the price of the allowances during the years of trading.

There are three phases of trading of EU ETS. Phase I (2005-2007), Phase II (2008-2012), Phase III (2013-2020) (for more details see [43]). If we are going to focus on the number of allocated allowances during the three phases, we observe that the allocated number of allowances to the firms was greater than the real and verified quantity of emissions (Table 1), suggesting a source of inefficiency in the market. Hence, this is an important reason to explain why the participation of the environmental groups in the ETS is essential for the efficiency of the system. The ENGOs will purchase part of (or even all) the over-allocated allowances. Furthermore, even if we will assume that the regulator has limited information on the real and actual level of emissions, and this is why he allocated allowances more than the verified emissions, then the ENGOs participation could "correct" this mistake which emanates from the regulator's asymmetric information, given that the ENGOs will purchase and withdrawn the over-allocated allowances.

If we focus on the price of the allowances during the three phases, we observe that for the first phase, the price of the allowances in European market had a range from around 30 to $0.03 €$ (Figure 1).

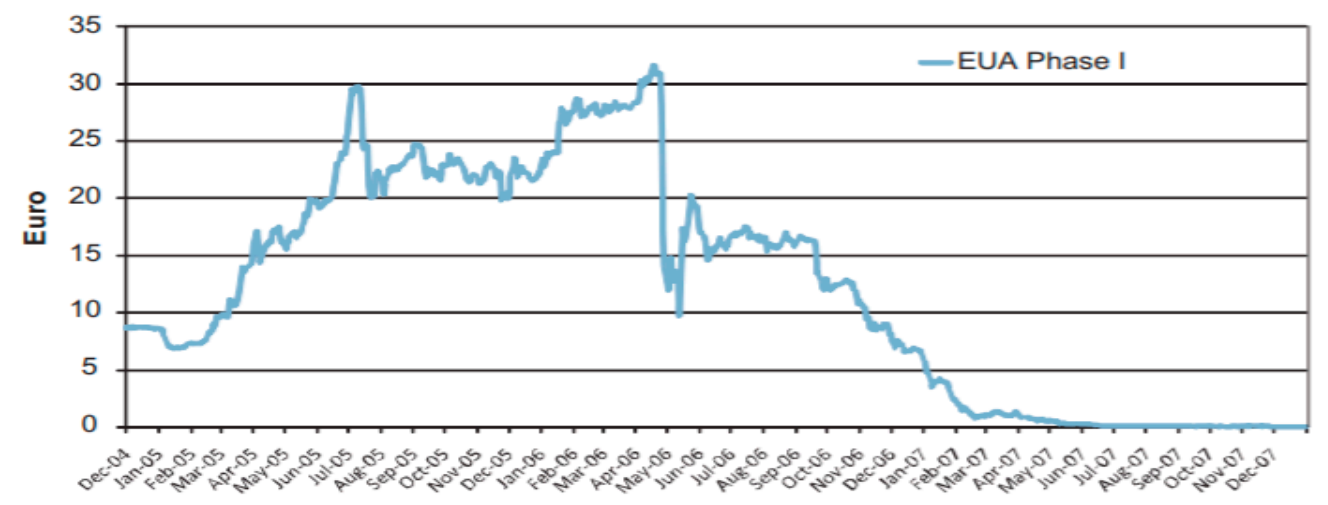

Figure 1. Price of European Union Allowances (EUA) for phase I. Source: [44].

Table 2 demonstrated that the regulator distributed several allowances more than the actual emissions; therefore, the available allowances in the market are more than the real emissions. This could lead to market distortion, and the collapsed of the allowance's price-since there is an oversupply of allowances. Moreover, we observe in Figure 1 the prices of the allowances during phase I, which reduced significantly during the second half of the phase. The collapsed of the price allowed the firms to pollute and purchase more "cheap" allowances rather than to invest in better technology for emissions' abatement. As it was mentioned before, we can see this behaviour in the statement from Acid Rain Retirement Fund and from Clean Air Conservancy (CAC). Furthermore, in a similar approach the policy of the Sandbag ENGO invites the public to destroy the carbon by purchasing allowances and take them out of the system. http://www.sandbag.org.uk/carbon/ (date access 8 September 2012). Similarly, with Sandbag, Clean Air Conservancy: "[W]ill purchase allowances for you and provide you with a "Clean Air Certificate" documenting the amount of pollution your contribution has prevented. 
The certificates may also be purchased as a gift for someone else." Source: http://www.epa.gov/ airmarkets/trading/buying.html (date access: 13 July 2013).

Table 2. Over-Allocated Allowances of $\mathrm{tCO}_{2}$-eq. in EU ETS for All Stationary Installations.

\begin{tabular}{cccc}
\hline & $\begin{array}{c}\text { Total Allocated } \\
\text { Allowances }\end{array}$ & Verified Emissions & $\begin{array}{c}\text { Over-Allocated } \\
\text { Allowances }\end{array}$ \\
\hline $\begin{array}{c}\text { Total 1st trading period } \\
\text { 2005-2007 }\end{array}$ & $6,369,571,429.00$ & $6,214,598,501.00$ & $154,972,928.00$ \\
\hline $\begin{array}{c}\text { Total 2nd trading period } \\
\text { 2008-2012 }\end{array}$ & $10,411,472,031.00$ & $9,709,509,339.00$ & $701,962,692.00$ \\
\hline $\begin{array}{c}\text { Total 3rd trading period } \\
\text { 2013-2020 }\end{array}$ & $11,457,702,320.00$ & $10,711,985,608.00$ & $745,716,712.00$ \\
\hline
\end{tabular}

Source: https://www.eea.europa.eu/data-and-maps/dashboards/emissions-trading-viewer-1 and calculations by the authors.

The same strategy is observed from carbonretirement.com which, as a broker, encourages the public to purchase and retire European allowances because: "[T]he heavily polluting industries that need them are required to reduce their emissions instead of buying allowances and continuing to pollute." http://www.carbonretirement.com/content/how it-works (accessed on 13 July 2013). So, the ENGOs aim to force firms to invest in low-carbon technology, creating long-term change and preventing emissions before they happen.

Thus, from the environmental groups' perspective, the over-allocation of allowances means that the firms could potentially pollute more, and at a relatively lower price, rather than have to invest in less polluting technology.

On the above graph, we see the changes in the price of the tradable allowances during phase II (2008-2012) and III (2013-2020). If we focus on the two graphs with the price of the tradable allowances during the years (Figures 1 and 2) we observe that there are periods where the price of the allowances is attractive or in other words is relatively low. Hence, from a financial perspective, this could indicate that for these periods a strategic collaborative movement of the ENGOs could be possible and that timing could encourage the decision of a group of ENGOs to collaborate and to move with a strategic plan in order to achieve the reduction of the maximum allowed emissions and to drive the allowances market to a lower level of the maximum quantity of allowances/emissions. For example, if we assume that a group of ENGOs collaborate and are characterised by rational behaviour or strategy, then we expect to see a purchasing movement when the prices are low. We present some examples where the prices are relatively attractive as these are mentioned in Figure 2. Specifically, we observe from Figure 2 that at 2 September 2009 the price is $9.20 €$, at 1 September 2012 the price is $6.77 €$, at 28 January 2013 the price is $3.85 €$, at 22 April 2013 the price is $2.97 €$, at 8 February 2016 the price is $4.97 €$, at 9 December 2016 the price is $4.11 €$, at 12 November 2017 the price is $7.14 €$, and at 29 October 2018 the price is $16.35 €$. It is reasonable to expect a higher demand for allowances during the specific periods, not only from the ENGOs, but also from the firms or any other participant, given the attractive price. To separate the ENGOs from the other buyers and to explore further this topic, we need to have more details for the volume of the allowances sold and purchased, as well as details for the buyers. However, these data are not available to the public (according to our knowledge), and a strategic movement like this by the ENGOs may be hampered by this lack of information. However, we hope that this study will encourage future research on this topic, although we recognised the possible limitations of this research. 


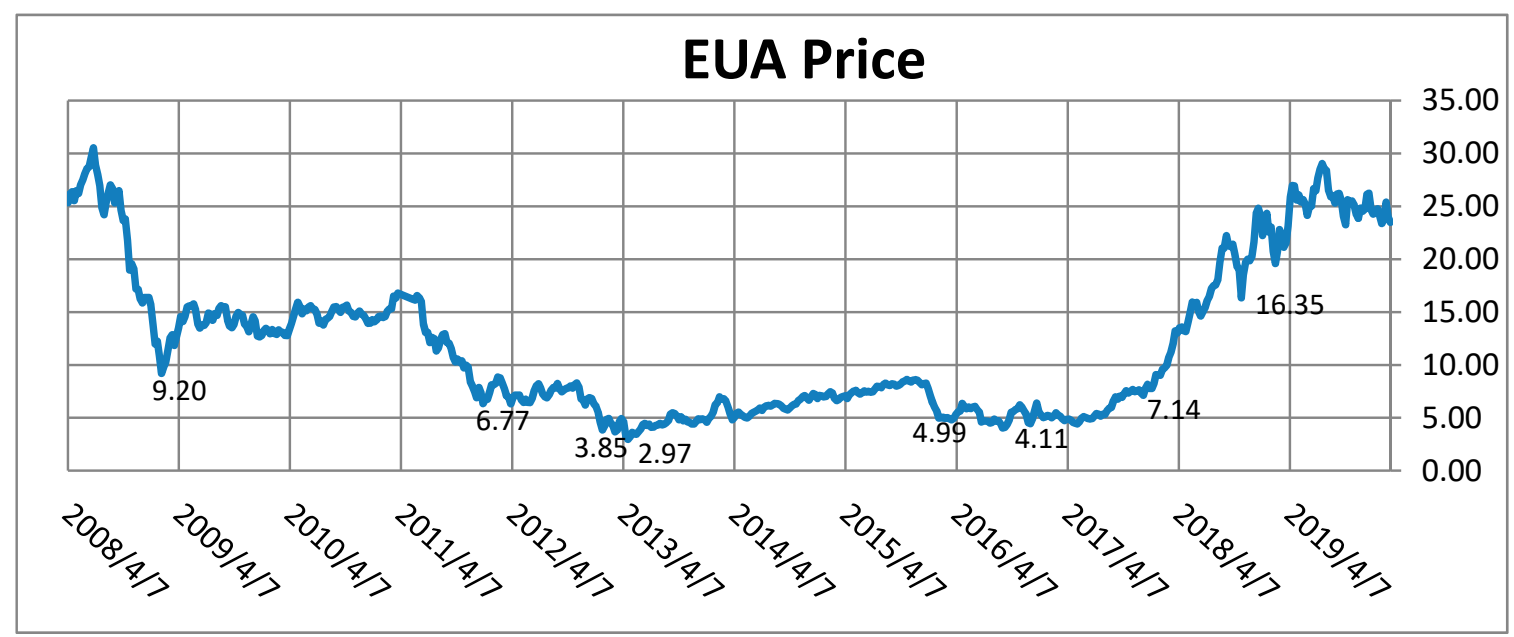

Figure 2. Price of European Union Allowances (EUA) for phases II and III. (4 July 2008-2 March 2020). Source: https://ember-climate.org/data/carbon-price-viewer/.

\section{Conclusions}

In this article, we focussed on the participation of the interest groups and third parties in the ETS-specifically, on the role of the environmental groups in the tradable allowances market. Environmental groups could share the aim of attempting to limit the amount of pollution in the environment via the EU ETS. A case like that could be the coalition of Green 10, the ten of the largest environmental organisations and networks active on the European level or the CAN Europe, Europe's leading NGO coalition fighting dangerous climate change.

Environmental groups could be a strategic player in the allowance markets, given that they could use part of their income to purchase and withdraw the unused allowances from the allowances market, following rational strategic behaviour. For the environmental groups, this participation in the ETS is a new strategy (different from the traditional strategies, e.g., lobbying, boycotting, etc.) for pressing the firms to adopt better and less polluting technologies in the pursuit of the lower level of emissions.

This political action probably has great potential to achieve change in an area where change seems very difficult. One of its captive aspects, in this respect, is that this action implies an attempt to create leverage in the same context and under the same terms of the industrial/business lobby field (i.e., fighting something on its own terms).

The ENGOs instead of lobbying the regulator for the reduction of the available allowances in the market, prefer to participate directly in the ETS in order to purchase and withdraw allowances as a way to drive the market to the "optimum" level of emissions. Here, it is important to note that the 'optimum' level of emissions is different for the environmentalists than it is for the regulator. For the regulator (and according to economic theory), the ideal point of emissions is where the marginal benefits of pollution are equal to the marginal damages. However, for the ENGOs, the optimum point does not follow the same principle. The lower the level of the allowances is, the less will be the potential level of the emissions, which is better for the conservation of the environment. Simply, the environmentalists place a much larger value on emission reduction than the regulator.

Hence, the initial allocation of the 'optimum' quantity of allowances is an important issue for the robustness, functionality, and prosperity of the system. In this case, the participation of ENGOs in the ETS may be crucial. When the regulator allocates several allowances more than the actual emissions for each period, the ENGOs (and third parties) can purchase the extra, over-allocated quantity of allowances.

The focuses of this study were to (i) highlight the dynamic of the environmental groups with respect to the European allowances market, and (ii) the emergence of the possible strategy of a coalition of ENGOs—-which may pursue strategic behaviour in the allowances market. Particularly, each group 
in the coalition could offer part of the income (or full income like ARRF,) in order to purchase and withdraw (at least) part of the excess allowances from the market and to reduce the maximum available level of the emissions.

What will happen depends on the group's priorities and strategies; but in this study, we highlight the increasing groups' interest in the allowances, and their possible influence on the number of available allowances in the market.

We believe that further analysis on the way that the environmental groups react against the environmental pollution using the tradable allowances is essential although there are limitations with respect to the availability of the data. We hope that this study will be a motivation for future research.

Author Contributions: Conceptualization, E.A. and T.W.-J.; investigation, E.A.; writing-original draft preparation, E.A.; writing-review and editing, T.W.-J.; supervision, E.A. and T.W.-J. All authors have read and agreed to the published version of the manuscript.

Funding: This research received no external funding.

Conflicts of Interest: The authors declare no conflict of interest.

\section{References}

1. Asproudis, E.; Gil-Molto, M.J. Pollution and Environmentalists' Participation in Emissions Trading Systems. Strat. Behav. Environ. 2014, 4, 59-87. [CrossRef]

2. Yang, P.; Kaffine, D. Community-Based Tradable Permits for Localized Pollution. Environ. Resour. Econ. 2015, 65, 773-788. [CrossRef]

3. Heberling, M.T.; Thurston, H.W.; Nietch, C.T. Exploring Nontraditional Participation as an Approach to Make Water Quality Trading Markets More Effective. JAWRA J. Am. Water Resour. Assoc. 2018, 54, 586-593. [CrossRef]

4. Asproudis, E. Revisiting environmental groups and members' behaviour: Budget, size and (im)pure altruism. Environ. Econ. Policy Stud. 2011, 13, 139-156. [CrossRef]

5. Israel, D. Environmental participation in the U.S. sulphur allowance auctions. Environ. Resour. Econ. 2007, 38, 373-390. [CrossRef]

6. Joskow, P.; Schmalensee, R.; Bailey, E. The market for sulfur dioxide emissions. Am. Econ. Rev. 1998, 88, 669-685.

7. Werker, E.; Ahmed, F.Z. What Do Nongovernmental Organizations Do? J. Econ. Perspect. 2008, 22, 73-92. [CrossRef]

8. United Nations. Handbook on Nonprofit Institutions in the System of National Accounts; ST/ESA/STAT/SER.F/91; United Nations Publication: New York, NY, USA, 2003; Sales no: E.03.XVII.9.

9. Coase, R.H. The Problem of Social Cost. J. Law Econ. 1960, 3, 1-44. [CrossRef]

10. Baumol, W.J.; Oates, W.E. The Theory of Environmental Policy, 2nd ed.; Cambridge University Press: Cambridge, MA, USA, 1988.

11. Crocker, T.D. The Structuring of Atmospheric Pollution Control Systems. In The Economics of Air Pollution; Wolozin, H., Ed.; W.W. Norton and Co: New York, NY, USA, 1966.

12. Dales, J.H. Pollution, Property and Prices; University of Toronto Press: Toronto, ON, Canada, 1968.

13. Gorman, H.S.; Solomon, B.D. The Origins and Practice of Emissions Trading. J. Policy Hist. 2002, 14, $293-320$. [CrossRef]

14. Heyes, A.; Liston, C.; Crew, M.; Parker, D. Economics of Environmental Regulation: Instruments and Cases. In International Handbook on Economic Regulation; Edward Elgar Publishing: Trotham, UK, 2013.

15. Kneese, A.V.; Schultze, C.L. Pollution, Prices and Public Policy; Brookings Institution: Washington, DC, USA, 1975.

16. Krupnick, A.J.; E Oates, W.; Van De Verg, E. On marketable air-pollution permits: The case for a system of pollution offsets. J. Environ. Econ. Manag. 1983, 10, 233-247. [CrossRef]

17. Mackintosh, D.R. The Economics of Airborne Emissions: The Case for an Air Rights Market; Praeger Publishers: New York, NY, USA, 1973.

18. Montgomery, W. Markets in licenses and efficient pollution control programs. J. Econ. Theory 1972, 5, 395-418. [CrossRef] 
19. Pearce, D. An Intellectual History of Environmental Economics. Annu. Rev. Energy Environ. 2002, $27,57-81$. [CrossRef]

20. World Commission on Environment and Development (WCED). Report of the World Commission on Environment and Development: Our Common Future; United Nations: New York, NY, USA, 1987.

21. Howes, M.; Wortley, L.; Potts, R.; Dedekorkut-Howes, A.; Serrao-Neumann, S.; Davidson, J.; Smith, T.F.; Nunn, P.D. Environmental Sustainability: A Case of Policy Implementation Failure? Sustainability 2017, 9, 165. [CrossRef]

22. Convery, F.J. Origins and Development of the EU ETS. Environ. Resour. Econ. 2009, 43, 391-412. [CrossRef]

23. Dolšak, N. Climate Change Policies in the Transitional Economies of Europe and Eurasia: The Role of NGOs. Volunt. Int. J. Volunt. Nonprofit Organ. 2012, 24, 382-402. [CrossRef]

24. Kim, S.E.; Urpelainen, J. When and how can advocacy groups promote new technologies? Conditions and strategies for effectiveness. J. Public Policy 2013, 33, 259-293. [CrossRef]

25. Kollmann, A.; Schneider, F. Why Does Environmental Policy in Representative Democracies Tend to Be Inadequate? A Preliminary Public Choice Analysis. Sustainability 2010, 2, 3710-3734. [CrossRef]

26. Wettestad, J.; Guldbrandsen, L.H. The Evolution of Carbon Markets: Design and Diffusion; Routledge: Abington, UK, 2018.

27. Wettestad, J.; Jevnaker, T. Rescuing EU Emissions Trading: The Climate Policy Flagship; Palgrave Macmillan: London, UK, 2016.

28. Anger, N.; Böhringer, C.; Oberndorfer, U. Public Interest vs. Interest Groups: Allowance Allocation in the EU Emission Trading Scheme; Discussion Paper No. 08-023; Centre for European Economic Research: Mannheim, Germany, 2008.

29. Goeree, J.K.; Holt, C.A.; Palmer, K.; Shobe, W.; Burtraw, D. An Experimental Study of Auctions Versus Grandfathering to Assign Pollution Permits; Discussion Paper; Resources for the Future: Washington, DC, USA, 2009; Volume RFF DP 09-39.

30. European Commission. Proposal for a Directive of the European Parliament and of the Council Establishing a Scheme for Greenhouse Gas Emission Allowance Trading within the Community and Amending Council Directive 96/61/E.C. COM (2001) 581 Final; European Commission: Brussels, Belgium, 2001.

31. UNFCCC. Review of the implementation of commitments and of other provisions of the convention. Preparations for the first session of the conference of the parties serving as the meeting of the parties to the Kyoto protocol (decision 8/cp.4). Decisions concerning guidelines under articles 5, 7 and 8 of the Kyoto protocol. FCCC/CP/2001/2/Add.4. 2001. Available online: https://digitallibrary.un.org/record/446739?ln=en (accessed on 11 August 2017).

32. European Commission. Directive 2003/87/E.C. of the European Parliament and of the Council of 13 October 2003 Establishing a Scheme for Greenhouse Gas Emission Allowance Trading within the Community and Amending Council Directive 96/61/E.C; European Commission: Brussels, Belgium, 2003.

33. Wapner, P. Politics beyond the State Environmental Activism and World Civic Politics. World Politics 1995, 47, 311-340. [CrossRef]

34. Carman, C.J. Brokering Interests: The Use of Market-Based Policies by Interest Groups. Soc. Sci. Q. 2002, 83, 137-155. [CrossRef]

35. Kruger, J.; Dean, M. Looking back on $\mathrm{SO}_{2}$ trading: What's good for the environment is good for the market. Public Util. Fortn. 1997, 135, 30-37.

36. Hahn, R.W.; Stavins, R.N. Incentive-based environmental regulation: A new era from an old idea? Ecol. Law Q. 1991, 18, 23-25.

37. McKibbin, W.J.; Wilcoxen, P.J. The Role of Economics in Climate Change Policy. J. Econ. Perspect. 2002, 16, 107-129. [CrossRef]

38. Tietenberg, T.H. Economic Instruments for Environmental Regulation. Oxf. Rev. Econ. Policy 1990, 6, 17-33. [CrossRef]

39. Schwarze, R.; Zapfel, P. Sulfur Allowance Trading and the Regional Clean Air Incentives Market: A Comparative Design Analysis of two Major Cap-and-Trade Permit Programs? Environ. Resour. Econ. 2000, 17, 279-298. [CrossRef]

40. Frank, R.H. The economist as public intellectual: A case for selling Pareto improvements. East. Econ. J. 2001, 27, 221-225. 
41. Tietenberg, T. The Tradable-Permits Approach to Protecting the Commons: Lessons for Climate Change. Oxf. Rev. Econ. Policy 2003, 19, 400-419. [CrossRef]

42. Smith, S.C.; Yates, A.J. Should Consumers Be Priced Out of Pollution-Permit Markets? J. Econ. Educ. 2003, 34, 181-189. [CrossRef]

43. Sattarhoff, C.; Gronwald, M. How to Measure Financial Market Efficiency? A Multifractality-Based Quantitative Approach with an Application to the European Carbon Market. In Proceedings of the 24th Annual Conference of the European Association of Environmental and Resource Economists, Manchester, UK, 26-29 June 2019.

44. Hintermann, B. Allowance price drivers in the first phase of the EU ETS. J. Environ. Econ. Manag. 2010, 59, 43-56. [CrossRef]

Publisher's Note: MDPI stays neutral with regard to jurisdictional claims in published maps and institutional affiliations.

(C) 2020 by the authors. Licensee MDPI, Basel, Switzerland. This article is an open access article distributed under the terms and conditions of the Creative Commons Attribution (CC BY) license (http://creativecommons.org/licenses/by/4.0/). 